\title{
Geometry and Stability of Molecular Clusters: Factor to Be Considered in Biomolecular Activity
}

\author{
Noam G. da Silva, ${ }^{a}$ Alexandre M. Alecrim, ${ }^{b}$ Renyer A. Costa ${ }^{a}$ and \\ Kelson M. T. de Oliveira*,a \\ ${ }^{a}$ Laboratório de Química Teórica e Computacional, Departamento de Química, \\ Universidade Federal do Amazonas, Campus Universitário, Setor Norte, \\ Av. Rodrigo O. J. Ramos, 6200, Japiim, 69077-000 Manaus-AM, Brazil \\ ${ }^{b}$ Instituto de Educação, Agricultura e Meio Ambiente, Universidade Federal do Amazonas, \\ Campus Vale do Rio Madeira, R. 29 de Agosto, 786, Centro, 69800-000 Humaitá-AM, Brazil
}

Betulinic and melaleucic acids, lupan-skeleton triterpenes with very similar structure, present marked differences in anti-malarial activity. While betulinic acid and some of its analogs exhibit strong activity, melaleucic acid is inactive. In the present work, a theoretical approach was used to explain such differences, using Austin Model 1 (AM1) and density functional theory (DFT)/ Becke, three-parameter, Lee-Yang-Parr (B3LYP) approaches, and AutoDock Vina calculations. The initial results showed no significant differences between structural and electronic properties. On the other hand, studies of the geometry of molecular clusters with both compounds revealed significant differences. Melaleucic acid clusters were shown to be stable enough to influence the substrate-protein interaction, unlike betulinic acid, which was unable to form clusters comparable to melaleucic acid ones. The present study suggests the molecular clusters as a new factor that has a great influence on the mechanism of biomolecular activity.

Keywords: betulinic acid, melaleucic acid, organic clusters, molecular docking, B3LYP

\section{Introduction}

The activities of organic compounds are closely associated with the characteristics of the individual molecules, such as geometry, functional groups and structural rigidity. Many studies with organic molecules use this association to explain biochemical activities, so that comparable activities of analogous compounds are easily explained. ${ }^{1-6}$ However, when analogous compounds exhibit distinct activities, the low-activity compound generally loses importance. Mostly, the reason for the difference in activities is ignored. In the present work, two analogous triterpenes having great structural similarity, betulinic acid (BetAc) and melaleucic acid (MelAc), were studied because of their very different biomolecular activities. They belong to the group of lupane pentacyclic triterpenes (LPT), whose basic skeleton can be seen in some compounds with activity against malaria (Figure 1).

*e-mail: kelsonmota@ufam.edu.br
Betulinic acid (3ß-hydroxy-lup-20(29)-en-28-oic acid) ${ }^{7}$ and its derivatives have received great atention for their activities against cancer, ${ }^{8-11} \mathrm{HIV},{ }^{12-14}$ and malaria. ${ }^{15} \mathrm{BetAc}$ also acts as an analgesic and anti-inflammatory agent, ${ }^{16-18}$ an antifeeding agent, ${ }^{19}$ and also has other important applications. ${ }^{1,20,21}$ On the other hand, melaleucic acid (3ß-hydroxy-lup-20(29)-en-27,28-dioic acid) ${ }^{7}$ has few studies and little data available in the literature, which might be associated with low biochemical activity of this compound. ${ }^{22}$ The studies about activity of BetAc against malaria are very important, since this disease is responsible for 216 million clinical cases annually, especially in the region where the present work has been developed. ${ }^{23-26}$ The mechanism of the activity of triterpenes against Plasmodium is still an objective of various studies. ${ }^{23,27,28}$ There are indications that the presence of more oxidized C28 leads to higher activities, as can be seen in the order of antiplasmodial activity: $-\mathrm{C} 28 \mathrm{OOH}>-\mathrm{C} 28 \mathrm{H}_{2} \mathrm{OH}>-\mathrm{C}_{2} 8 \mathrm{H}_{3} .{ }^{29}$

Surprisingly, in vitro tests against Plasmodium showed the inactivity of MelAc in comparison with other LPT 


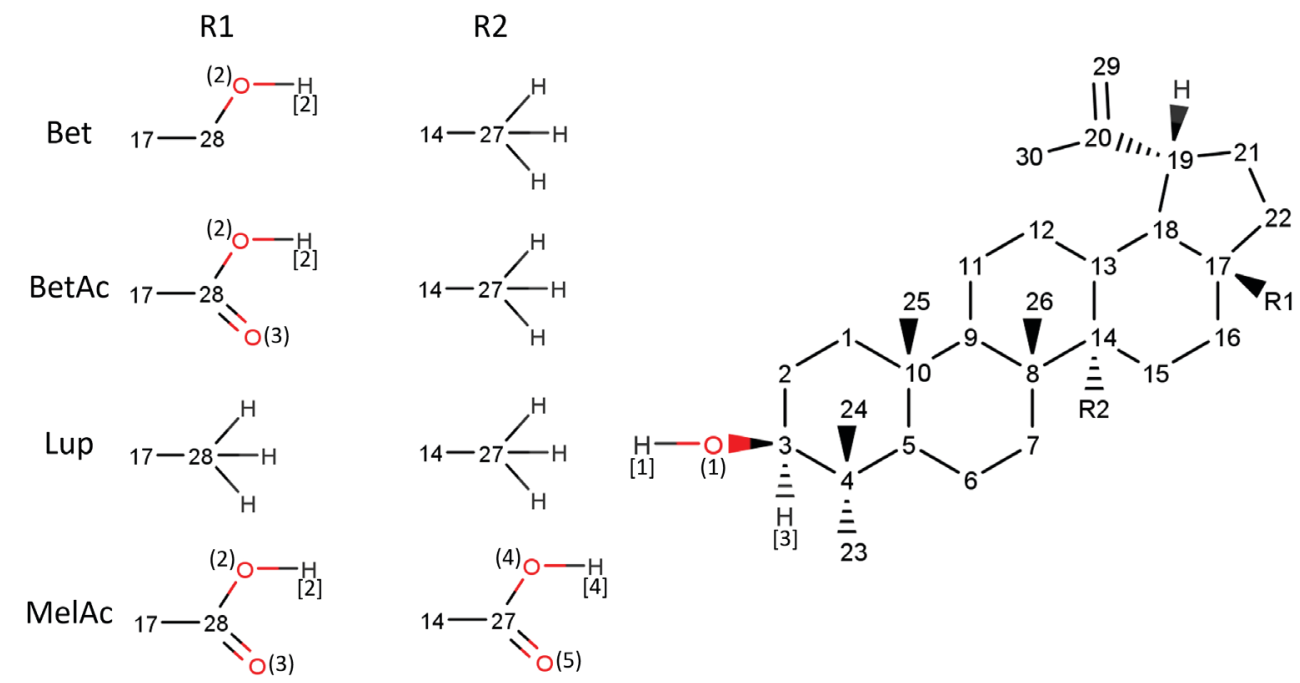

Figure 1. Common lupane pentacyclic triterpenes (LPT) with carbons numbered, oxygen numbers in parentheses and hydrogens numbers in brackets.

analogs (BetAc, lupeol (Lup) and betulin (Bet)), as can be seen in the results published by Carmo et al. ${ }^{30}$ (Table S1, Supplementary Information (SI) section). The four LPT were tested against two strains of P. falciparum, and three of them exhibited good activity, but MelAc was inactive, with half maximal inhibitory concentration $\left(\mathrm{IC}_{50}\right.$, in $\left.\mu \mathrm{M}\right)$ of 508.74 for 3D7 and 710.10 for Dd2. Considering as a structural reference the main polar groups at $\mathrm{C} 3$ and $\mathrm{C} 17$ of BetAc, it is evident that the MelAc is the closest analog. Lupeol and betulin have very different groups at these positions. We attempt to explain the observed inactivity as the effect of the carboxyl in C27, which implies in a polar (hydrophilic) region in MelAc. Considering BetAc, betuline and lupeol, which exhibit higher activities compared to MelAc, it can be considered that the region should be nonpolar (hydrophobic). However, there are studies demonstrating that the $\mathrm{C} 27$ region may be hydrophilic, and lead to higher activity compared to BetAc. ${ }^{31}$ Another aspect suggestive that the effect of an additional carboxyl should not be so impacting is precisely that lupeol (with $\mathrm{C}_{2} 8 \mathrm{H}_{3}$ ) has activity comparable to BetAc (with $\mathrm{C} 28 \mathrm{OOH}$ ). If the LPT have comparable activities when $\mathrm{C} 28$ is either a carboxyl or a methyl, then MelAc should not display inactivity. ${ }^{29}$ With no explanation for this anomalous behavior in the literature, the real reason for MelAc inactivity remains a mystery.

Since BetAc and MelAc are close analogs, the difference in activities may be due to two causes: (i) a fundamental difference in some structural or electronic properties between the triterpenes; and (ii) an extramolecular factor, during the interaction and organization between several molecules, while forming stable molecular agglomerates (clusters). This last possibility is based on the fact that molecular clusters are capable of influencing compound properties and process dynamics. ${ }^{32-34}$ Both above-mentioned possibilities were investigated in this work. Molecular clusters present variable sizes, depending on structural possibilities and availability of molecules in medium. ${ }^{35}$ The trend in cluster formation is associated with thermodynamics and kinetics. They are not favored entropically due to the increase in molecular organization, but theoretical studies point to the possibility of stable geometry of these clusters when the interactions outweigh or diminish the repulsive effects of the medium. ${ }^{36-40}$ In general, compounds capable of forming hydrogen bonds can be organized in stable clusters. ${ }^{41-44}$ Organic molecules capable of forming clusters with hydrogen bonds and other types of interactions have been explored with theoretical and experimental approaches. ${ }^{32,33,45-49}$ In this context, it is possible that several organic properties are associated with molecular clusters, and not only with individual molecules..$^{50,51}$

Thus, the present work investigated the individual molecules of BetAc and MelAc by theoretical approaches, and the results were compared with experimental data. Since the preliminary study did not show significant differences between electronic and structural properties of individual molecules, we also investigated clusters of these compounds, with mixed density functional theory and semi-empirical approaches.

\section{Methodology}

Theoretical calculations were performed at the Laboratório de Química Teórica e Computacional (LQTC), Universidade Federal do Amazonas (UFAM), in microcomputers with Intel ${ }^{\circledR}$ Core $^{\mathrm{TM}}$ processors with 8 cores, 16 GB random access memory (RAM), using Debian Linux 64-bit (version 7) operating system. The 
software Gaussian $09^{52}$ was used for geometry optimization and other calculations.

We used Austin Model 1 (AM1) and density functional theory (DFT) with Becke, three-parameter, Lee-Yang-Parr (B3LYP) hybrid functional. These approaches were applied to optimization calculations, total single point energy $\left(\mathrm{E}_{\mathrm{T}}\right)$, infrared (IR) and Raman frequencies, molecular electrostatic potential surfaces (MEPS) and dipole moment $(\mu)$. The AM1 approach was chosen due to the low computational cost and quality of results, especially with respect to the optimization of cluster geometry. The B3LYP approach was used in more demanding calculations, with different base functions sets. Implicit solvation used Tomasi's integral equation formalism (IEF)-polarizable continuum model (PCM) (for $\mathrm{CHCl}_{3}$ and $\left(\mathrm{CH}_{3}\right)_{2} \mathrm{SO}$ ). ${ }^{53}$ For nuclear magnetic resonance (NMR) spectra the continuous set of gauge transformations (CSGT) model was used, considering $\mathrm{CHCl}_{3}$ IEF-PCM solvation.

The initial approximate geometries of BetAc and MelAc were adjusted based on parameters obtained from the absolute experimental configuration of 3-acetyl-betulinic acid, a derivative of BetAc. ${ }^{54}$ Systems with two (2M) and three $(3 \mathrm{M})$ molecules were modeled with isolated optimized molecules (Figure 2). In $2 \mathrm{M}$ and $3 \mathrm{M}$ systems, $\mathrm{C} 3 \mathrm{OH}$ groups were oriented to $\mathrm{C} 28 \mathrm{OOH}$ groups, favoring the formation of hydrogen bonds during optimization. The $2 \mathrm{M}$, therefore, presented two regions containing hydrogen bonds, and 3M three of those regions. The molecular docking was performed with AutoDock Vina (AD Vina) using AutoDock Tools interface. ${ }^{55}$ BIOVIA Discovery Studio $2017^{56}$ and MarvinSketch ${ }^{57}$ were also used in the manipulation of results and calculation of some properties. The molecular docking was performed with eight proteins from the Protein Data Bank (PDB) selected following these considerations: (i) human serum albumin (HSA), because of its ability to carry substances through the body; (ii) proteins associated with malaria, due to the focus of the present study; (iii) proteins complexed with chloroquine, a compound with high activity against Plasmodium; and (iv) peroxisome proliferator-activated receptor gamma (PPAR- $\gamma$ ) complexed with BetAc, to compare the binding conformations of the compounds. The docking calculations were performed at fourteen binding protein regions (PR) defined according to the numbers of ligands. The grid box configurations were defined first by the location and size of original ligands $(\mathrm{OL})$. After redocking of OL, new binding sites to the new ligands (NL) were found by box size expansion. The NL in the present work were BetAc, MelAc, Bet and Lup. The NL structures were also adapted from experimental absolute configuration, and optimized with B3LYP/6-311G(2d,p) approach. ${ }^{54}$
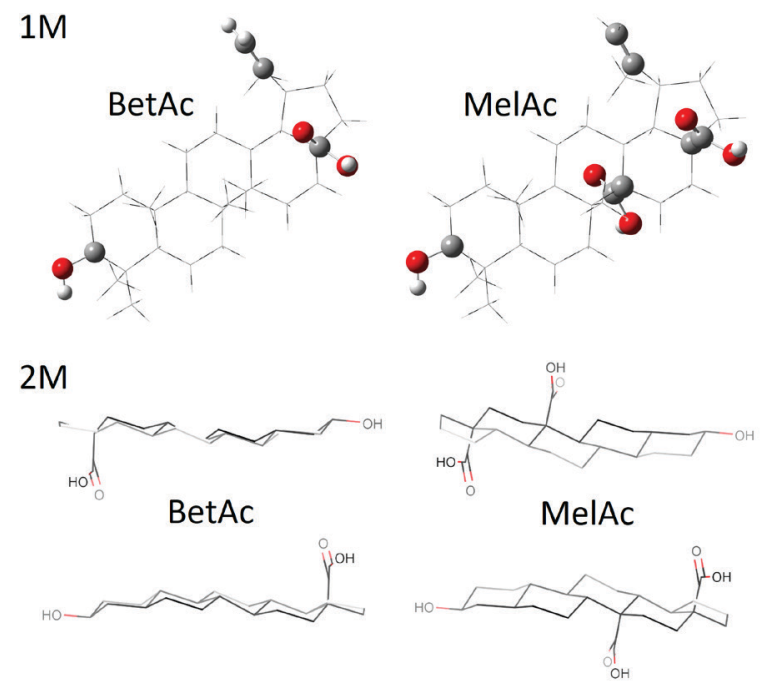

$3 \mathrm{M}$
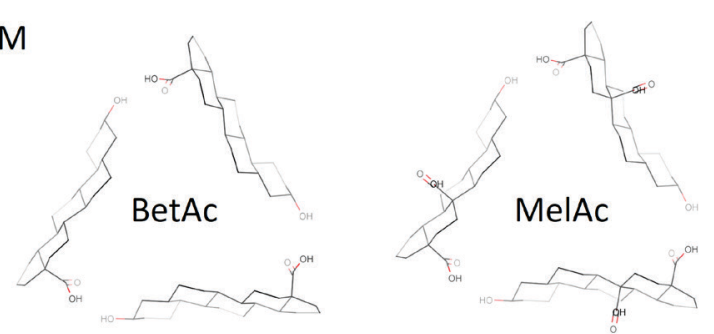

Figure 2. Isolated optimized molecules, highlighting the carboxyl, hydroxyl and ethyl groups, and model structures with two (2M) and three $(3 \mathrm{M})$ molecules.

\section{Results and Discussion}

Isolated molecules of BetAc and MelAc

Initially we analyze the isolated molecules of BetAc and MelAc (without intermolecular interactions) while searching for differences that could justify the great difference between their activities. The total single point energy $\left(E_{T}\right)$ indicates that BetAc is in a higher level of energy than MelAc, which suggests that, at $\mathrm{C} 14$ position, $\mathrm{COOH}$ leads to lower energies than $\mathrm{CH}_{3}$ (Table S2, SI section). The IEF-PCM implicit solvation by $\mathrm{CHCl}_{3}$ and $\left(\mathrm{CH}_{3}\right)_{2} \mathrm{SO}$ results in the variations of total energy by solvation $(\Delta \mathrm{E})$ for BetAc and MelAc (also in Table S2). The $\mu$ of solvents and LPT (obtained by B3LYP/6-311G(2d,p)//AM1 approach in gas phase) corroborates with the greater stabilization of MelAc. The $\left(\mathrm{CH}_{3}\right)_{2} \mathrm{SO}(\mu=3.959 \mathrm{D})$ stabilizes polar compounds more than $\mathrm{CHCl}_{3}(\mu=1.095 \mathrm{D})$. The MelAc, with $\mu$ of $2.884 \mathrm{D}$, has more negative $\Delta \mathrm{E}$ than BetAc, with $\mu$ of $1.949 \mathrm{D}$, and in addition MelAc has more polar groups, which leads to better accommodation in IEF-PCM solvation cavity.

The theoretical geometric data were compared with results obtained by X-ray diffraction for methyl 
melaleucate iodoacetate, a derivative of MelAc (Figure S1, SI section), and the values had great proximity. ${ }^{58}$ The small differences between the compounds are due to the presence of additional carboxyl in MelAc. Similarly, the theoretical interatomic angles between the compounds present great overlap, with slight variations (Figure S2, SI section). These results show that the compounds have very similar geometry, even MelAc having a volume around $10 \%$ larger. The two optimization approaches exhibit close data, which allowed us to proceed with combined B3LYP//AM1 calculations.

The theoretical spectra of IR, Raman and ${ }^{13} \mathrm{C}$ NMR for BetAc and MelAc were also close to experimental ones..$^{20,59-61}$ The IR stretchings (Figure S3, SI section) associated with $\mathrm{O}-\mathrm{H}$ bonds in carboxyls and hydroxyls of BetAc are close to MelAc, but occur with higher energy for BetAc (Table S3, SI section). Most of the calculated frequencies are larger than the experimental ones. This indicates that the vibrations for molecules in gas phase are more energetic than those for crystalline systems, which may be the result of packaging effects and intermolecular interactions in the crystals, and in addition to the consideration of only harmonic vibrations in theoretical approaches.

The theoretical Raman spectra of BetAc and MelAc were also very similar (Figure S4, SI section). The ${ }^{13} \mathrm{C}$ NMR calculations also did not show a large difference between BetAc and MelAc (Figure S5, SI section). ${ }^{20}$ The theoretical chemical shifts presented slightly higher values than experimental, since they were calculated in gas phase, without the couplings that occur in solution.

The differences between the energies of the highest energy occupied molecular orbital (HOMO) and the lowest energy unoccupied molecular orbital (LUMO) result in the HOMO-LUMO energy gap ( $\left.\mathrm{E}_{\mathrm{HOMO}-\mathrm{LUMO}}\right)$, a property associated with the rigidity/motility of molecules and ions. The concept of rigidity $(\eta)$ is related to the reactivity of compounds, being a measure of the extent of chemical reactivity at which the addition of a charge stabilizes the system. Mathematically, $\eta$ is equivalent to half the difference between the ionization potential I (with $\mathrm{I}=-\mathrm{E}_{\mathrm{HOMO}}$ ) and the electroaffinity $\mathrm{A}$ (with $\mathrm{A}=-\mathrm{E}_{\mathrm{LUMO}}$ ). Hard substances tend to react with hard ones, and soft substances with soft ones (hard-soft-acid-base theory). ${ }^{62}$

In general, the chemical reactivity is higher for LUMO of lower energies and HOMO of higher energies, that is, when the gap is small (soft ones). A greater hardness indicates more stable molecules, and a greater softness indicates higher chemical reactivity. Two other important descriptors are the chemical potential $\left(\mu_{\mathrm{P}}\right)$, related to capacity of the transfer of charge from a system with a higher chemical potential to one with lower chemical potential, and electronegativity $(\chi)$, related to capacity to attract electrons (is numerically equal to negative of $\mu_{\mathrm{P}}$ ). It is also interesting to compare the electrophilicity indexes $(\omega)$ of both compounds. The parameter $\omega$ is a global reactivity index, related to both $\eta$ and $\mu_{\mathrm{p}}$, and measures the overall electrophilic nature of a molecule, indicating the energy drop due to a charge transfer in a reactive system. Thus, an organic molecule can be classified as strongly $(\omega>1.5 \mathrm{eV})$, moderately $(\omega=0.8-1.5 \mathrm{eV})$, and marginally $(\omega<0.8 \mathrm{eV})$ electrophilic. The inverse of electrophilicity $(1 / \omega)$ results in nucleophilicity. These descriptors are defined in equation 1:63-65

$$
\eta=\frac{(\mathrm{I}-\mathrm{A})}{2} ; \mu_{\mathrm{P}}=\frac{-(\mathrm{I}+\mathrm{A})}{2} ; \chi=\frac{(\mathrm{I}+\mathrm{A})}{2} ; \omega=\frac{\mu^{2}}{2 \eta}
$$

The results (Table 1) show that MelAc is slightly more reactive than BetAc, which can be verified by its lower rigidity index. Therefore, MelAc, showing greater motility/softness, should react more easily than BetAc, even

Table 1. Electronic parameters for isolated molecules (1M), and for $2 \mathrm{M}$ and $3 \mathrm{M}$ systems, obtained by AM1 approach in gas phase

\begin{tabular}{|c|c|c|c|c|c|c|}
\hline \multirow{3}{*}{ Parameter } & \multicolumn{6}{|c|}{ Value / $\left(\mathrm{kJ} \mathrm{mol}^{-1}\right)$} \\
\hline & \multicolumn{3}{|c|}{ BetAc } & \multicolumn{3}{|c|}{ MelAc } \\
\hline & $1 \mathrm{M}$ & $2 \mathrm{M}$ & $3 \mathrm{M}$ & $1 \mathrm{M}$ & $2 \mathrm{M}$ & $3 \mathrm{M}$ \\
\hline $\mathrm{E}_{\text {номо }}$ & -40.248 & -40.332 & -40.159 & -40.187 & -40.352 & -40.233 \\
\hline $\mathrm{E}_{\text {LUMO }}$ & 4.820 & 4.448 & 5.040 & 4.179 & 3.763 & 4.083 \\
\hline $\mathrm{E}_{\text {Hомо-Lumo }}$ & 45.067 & 44.781 & 45.200 & 44.365 & 44.115 & 44.316 \\
\hline Hardness $(\eta)$ & 22.533 & 22.390 & 22.600 & 22.183 & 22.058 & 22.158 \\
\hline Chemical potential $(\mu)$ & -17.714 & -17.942 & -17.559 & -18.004 & -18.294 & -18.075 \\
\hline Electronegativity $(\chi)$ & 17.714 & 17.942 & 17.559 & 18.004 & 18.294 & 18.075 \\
\hline Electrophilicity index $(\omega)$ & 6.962 & 7.189 & 6.822 & 7.306 & 7.586 & 7.372 \\
\hline
\end{tabular}

BetAc: betulinic acid; MelAc: melaleucic acid; $\mathrm{E}_{\text {номо }}, \mathrm{E}_{\mathrm{Lumo}}$ : energies of the highest energy occupied molecular orbital (HOMO) and the lowest energy unoccupied molecular orbital (LUMO), respectively; $\mathrm{E}_{\text {Hомо-LUмо }}$ : HOMO-LUMO energy gap; 1M, 2M, 3M: systems with isolated, two and three molecules, respectively. 
in biochemical processes. Both compounds have $\omega$ much smaller than $0.8 \mathrm{eV}$, clearly showing nucleophilic characteristics $(\omega$-BetAc is $0.0721 \mathrm{eV}$, and $\omega$-MelAc is $0.0757 \mathrm{eV}$ ). Therefore, the presence of an extra carboxyl in LPT skeleton influences in reactivity of molecule.

Many models use the distribution of molecular charges to help understand how the substrate-protein interactions occur. Thus, proteins tend to interact with analogous compounds which preserve the molecular electrostatic potential surface (MEPS). Blue regions indicate low electronic density and high concentration of positive charges. Red regions indicate high electronic density and high concentration of negative charges. Regions of predominant nonpolarity appear in green.

Ignoring the difference in C27, we can say that MEPS are very similar for BetAc and MelAc (Figure 3). The additional carboxyl group at $\mathrm{C} 14$ position did not cause significant changes in MelAc distribution of charges in C3 and $\mathrm{C} 17$ regions (when compared to BetAc). The MEPS for BetAc indicates high concentration of negative charges at the $\mathrm{O} 1$ of $\mathrm{C} 3 \mathrm{OH}$, and dispersedly at the pentacyclic ring together with $\mathrm{O} 3$ of $\mathrm{C} 28 \mathrm{OOH}$. The high concentration of positive charges occurs at $\mathrm{H} 2$ of $\mathrm{C} 28 \mathrm{OOH}$ and more weakly at $\mathrm{H} 1$ of $\mathrm{C} 3 \mathrm{OH}$. The MEPS for MelAc shows basically the same regions as BetAc, with the addition of a new high concentration of positive charges at $\mathrm{H} 4$ of $\mathrm{C} 27 \mathrm{OOH}$, and a high concentration of negative charges, with lower intensity, on the atom $\mathrm{O} 4$, also in $\mathrm{C} 27 \mathrm{OOH}$.
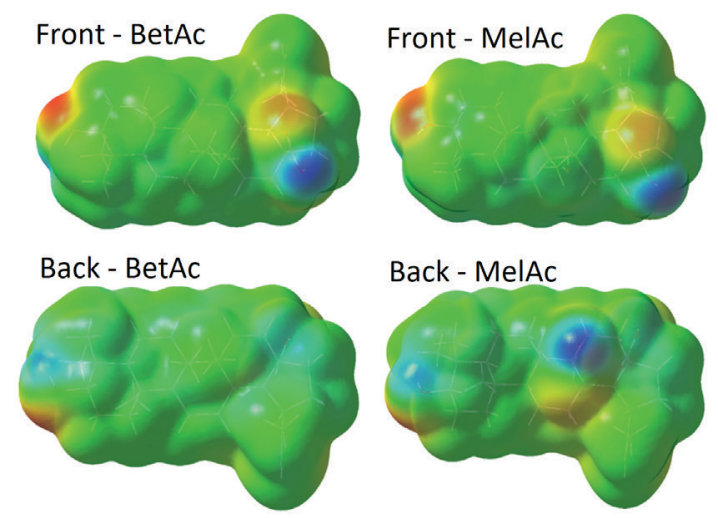

Figure 3. Front and back view of BetAc and MelAc MEPS obtained by B3LYP/6-311G//AM1 approach in gas phase.

The comparative calculations for BetAc and MelAc did not reveal any factor that could point out the cause for the large difference in activity. One would expect a fundamental difference in the electron structure with the addition of another carboxyl at the $\mathrm{C} 27$ position, but the IR, ${ }^{13} \mathrm{C}$ NMR, Raman, and MEPS show no significant differences. As no intramolecular differences were found, we explored intermolecular factors capable of influencing the activity of these compounds, since the presence of hydroxyls and carboxyls allow the formation of hydrogen bonds.

\section{$2 \mathrm{M}$ and $3 \mathrm{M}$ systems}

The stability of systems with $\mathrm{n}$ aggregate molecules $(2 \mathrm{M}, 3 \mathrm{M}, \mathrm{nM})$ can be calculated with respect to the energies of isolated molecule $\left(\mathrm{E}_{\text {(isolated molecule }}\right)$ by equation 2 , where $\mathrm{E}_{\mathrm{S}}$ is the stabilizing energy and $E_{n M}$ is the energy of the system with $n$ aggregated molecules. The lower the $\mathrm{E}_{S}$, the more stable the structure.

$\mathrm{E}_{\mathrm{s}}=\mathrm{E}_{\mathrm{nM}}-\mathrm{n} \times \mathrm{E}_{\text {(isolated molecule) }}$

The results indicate that the hydrogen bonds stabilize larger systems (Table 2), favoring the approximation of molecules until the point of forming aggregates. The formation of 2M systems (Figure S6, SI section) is not favored, since there is an increase in energy. The negative values of $E_{S}$ indicate a substantial decrease in the energy of $3 \mathrm{M}$ systems (Figure S7, SI section), which is much more stable than $1 \mathrm{M}$ and $2 \mathrm{M}$ systems.

Table 2. Stabilization energy $\left(E_{S}\right)$ associated with intermolecular interactions in the formation of $\mathrm{nM}$ molecular systems, obtained by B3LYP/6-31+G(2d, p)//AM1 approach in gas phase and with IEF-PCM implicit solvation

\begin{tabular}{lcccc}
\hline \multirow{2}{*}{ Compound } & \multicolumn{4}{c}{$\mathrm{E}_{\mathrm{S}} /\left(\mathrm{kJ} \mathrm{mol}^{-1}\right)$} \\
\cline { 2 - 5 } & $\begin{array}{c}2 \mathrm{M} \text { in gas } \\
\text { phase }\end{array}$ & $\begin{array}{c}3 \mathrm{M} \text { in gas } \\
\text { phase }\end{array}$ & $\begin{array}{c}3 \mathrm{M} \text { with } \\
\mathrm{CHCl}_{3}\end{array}$ & $\begin{array}{c}3 \mathrm{M} \text { with } \\
\left(\mathrm{CH}_{3}\right)_{2} \mathrm{SO}\end{array}$ \\
\hline BetAc & 17.051 & -68.557 & -37.637 & -24.975 \\
MelAc & 9.423 & -59.724 & -29.345 & -17.122 \\
\hline
\end{tabular}

$\mathrm{E}_{\mathrm{S}}$ : stabilization energy; 2M, 3M: systems with two and three molecules, respectively; BetAc: betulinic acid; MelAc: melaleucic acid.

The 3M-BetAc has greater $\mathrm{E}_{\mathrm{S}}$ than 3M-MelAc, indicating that the additional carboxyl has negative impact on stabilization. This is a reflection of the acceptor effect of the additional carboxyl at $\mathrm{C} 14$, which causes a decrease in intensity of the hydrogen bonds involving the $\mathrm{C} 28 \mathrm{OOH}$ on the opposite side of the structure. However, the maximum aggregation for BetAc involves three molecules. On the other hand, 3M-MelAc can form clusters with several $3 \mathrm{M}$ systems, with hydrogen bonds between additional carboxyls at $\mathrm{C} 14$ position. The solvated 3M was much more stable than the $2 \mathrm{M}$. However, in comparison with gas phase, the solvated $3 \mathrm{M}$ exhibited about half of stability with $\mathrm{CHCl}_{3}$ and slightly more than one third of stability with $\left(\mathrm{CH}_{3}\right)_{2} \mathrm{SO}$, suggesting that in gas phase the intermolecular interactions occur more effectively. Nevertheless, the 
values in solvated condition are high enough to allow the momentary formation of stable $3 \mathrm{M}$ structures in solution.

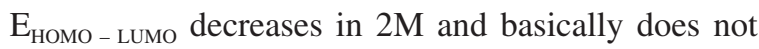
change in $3 \mathrm{M}$, both compared to $1 \mathrm{M}$ (Table 1). The lower $\eta$ values of $2 \mathrm{M}$ indicate that it is softer and thus more reactive or unstable. The higher $\eta$ values of $3 \mathrm{M}$ indicate that it is a more stable aggregate than $2 \mathrm{M}$ systems. For

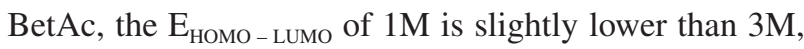
while for MelAc it is inverse. This indicates that for MelAc, $3 \mathrm{M}$ is somewhat more reactive than $1 \mathrm{M}$, and for BetAc, $3 \mathrm{M}$ is less reactive than $1 \mathrm{M}$. The chemical potential $\left(\mu_{\mathrm{P}}\right)$ of the 3M-MelAc, being lower than 3M-BetAc, indicates the possibility of formation of a more stable cluster, as the electrophilicity index is well below $0.8 \mathrm{eV}$ for both compounds.

The theoretical IR spectra for $1 \mathrm{M}$ and $3 \mathrm{M}$ were compared and exhibited significant variation for the region of $\mathrm{O}-\mathrm{H}$ bonds (Figure 4). The increase in the number of symmetrical vibrations (due to the presence of more molecules) causes an increase in intensity of peaks in comparison with $1 \mathrm{M}$, but occurs in nearby regions. The $1 \mathrm{M}$ peaks at $3831.50 \mathrm{~cm}^{-1}$ (stretching $\mathrm{O} 1-\mathrm{H} 1$ ) and $3742.00 \mathrm{~cm}^{-1}$ (stretching $\mathrm{O} 2-\mathrm{H} 2$ ) occur with lower vibrational energy in $3 \mathrm{M}$ because of hydrogen bonds. In addition, three peaks occur in this region for 3M-MelAc, as an effect of polar interactions. When hydrogen bonds occur in MelAc, C27OO-H and C28OO-H vibrate differently, showing distinct peaks. The signals at 3130.58 and $3067.74 \mathrm{~cm}^{-1}$ are associated with stretching of $\mathrm{C} 20 \mathrm{C} 29-\mathrm{H}$ bond (double bond region). This region is not affected by the hydrogen bonds and its signals are not displaced in the $3 \mathrm{M}$. Most of LPT skeleton does not participate in polar interactions, and thus the signals do not suffer significant modification in 3M. Theoretical Raman spectra also show that the signals of O-H occur with less energy (Figure 5). As in IR spectra, a third peak occurs for 3M-MelAc in $3750 \mathrm{~cm}^{-1}$ (region associated with the $\mathrm{O}-\mathrm{H}$ bonds), also because polar interactions cause a differentiation in the vibration modes of C27OO-H and C28OO-H.

The results of IR and Raman suggest that the vibrations of $\mathrm{O} 1-\mathrm{H} 1$ and $\mathrm{O} 2-\mathrm{H} 2$ in $3 \mathrm{M}$ systems are closer to experimental. This indicates that hydrogen bonds contribute to the real structure of these compounds. Such aspect may also be important to the stabilization of these compounds in solution, which supports the idea of molecular clusters.

The analysis of MEPS of $2 \mathrm{M}$ and $3 \mathrm{M}$ for both compounds indicates that the LPT skeletons do not suffer significant impact of hydrogen bonds (Figure 6). The redistribution of electronic density occurs most significantly in the regions of polar interactions. In $2 \mathrm{M}$, besides the hydrogen bonds, LPT skeletons are stabilized by London
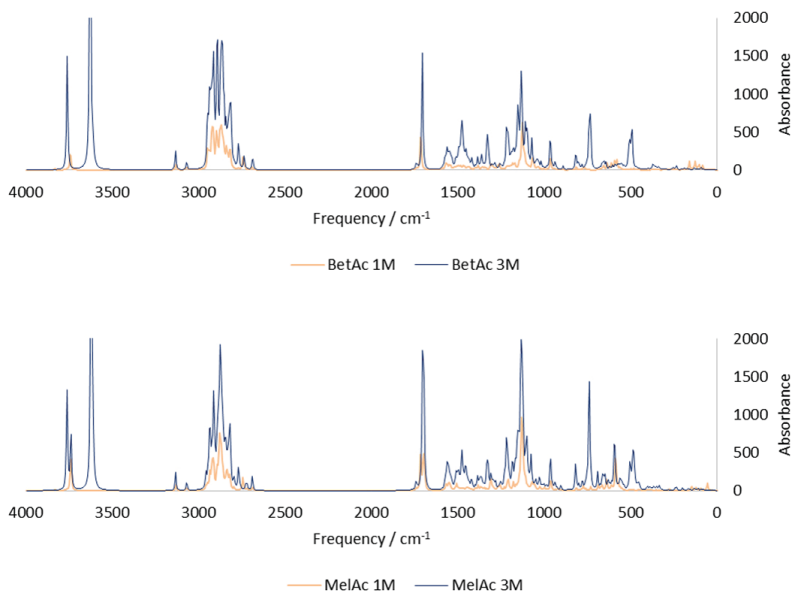

Figure 4. Theoretical IR spectra for BetAc (top) and MelAc (bottom) obtained by B3LYP/6-31G(d) approach in gas phase.
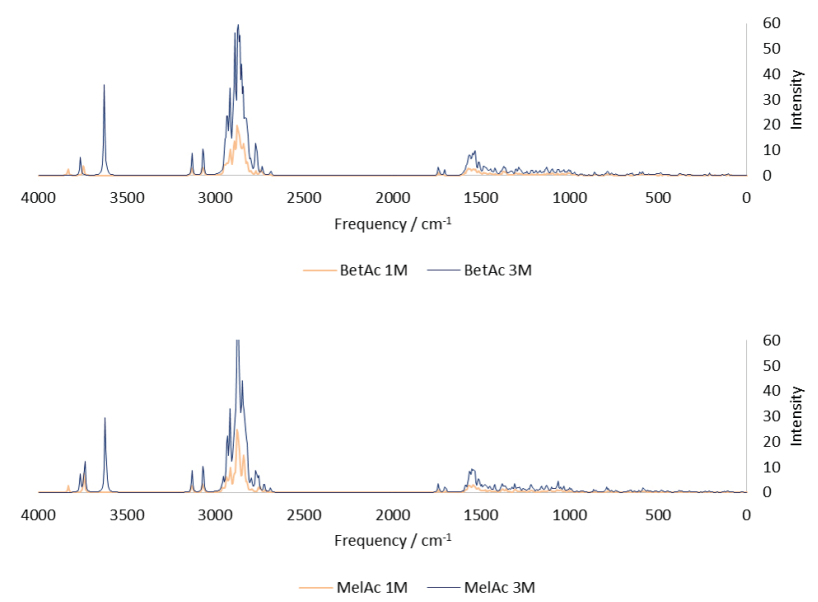

Figure 5. Theoretical Raman spectra for BetAc (top) and MelAc (bottom) obtained by B3LYP/6-31G(d) approach in gas phase.

interactions and the result is a slight increase in electronic density between skeletons. The concentrations of charges in $2 \mathrm{M}$ and $3 \mathrm{M}$ are weaker than in $1 \mathrm{M}$, but occur in the same regions. It is evident that the polar interactions are not very effective in $2 \mathrm{M}$ (less stable than $1 \mathrm{M}$ ), and the contribution of London interactions are not so significant. At $3 \mathrm{M}$ center a region is formed with no electronic density. This is because the LPT skeletons are far apart, so the London interactions are not favored. These results are in accordance with the energetic and geometric data, and explains the lower energy of $3 \mathrm{M}$, where the hydrogen bonds are more effective.

\section{Clusters and activity}

The additional carboxyl gives the MelAc a distinct property, which is also important for the $3 \mathrm{M}$ structures: the ability to form new stable hydrogen bonds with other $3 \mathrm{M}$ systems, resulting in larger aggregates. Thus, we model the $4(3 \mathrm{M})$-MelAc cluster (Figure 7), a structure where 

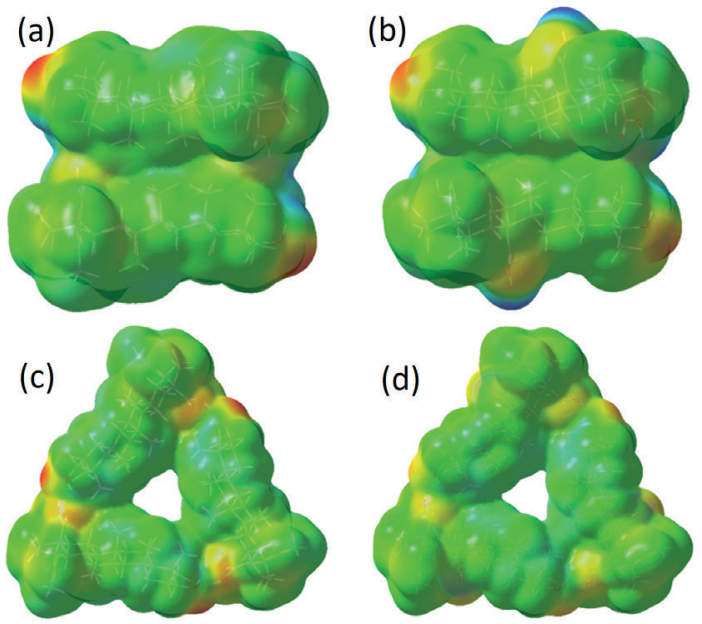

Figure 6. MEPS for (a) $2 \mathrm{M}-\mathrm{BetAc}$ and (b) $2 \mathrm{M}-\mathrm{MelAc}$, and for (c) 3M-BetAc and (d) 3M-MelAc, obtained by B3LYP/6-311G//AM1 approach in gas phase.

four $3 \mathrm{M}$ bind to the exposed $\mathrm{C} 27 \mathrm{OOH}$. In this structure, other $\mathrm{C} 27 \mathrm{OOH}$ groups are exposed, which allows for more polar interactions, enabling MelAc to form aggregates that expand with the availability of molecules. Overlapping two 4(3M)-MelAc clusters and directing polar interactions, we have the 2[4(3M)]-MelAc cluster, which resembles a closed shell. With 24 MelAc molecules, the 2[4(3M)]-MelAc structure has $24 \mathrm{COOH} \leftrightarrow \mathrm{COH}$ interactions and $12 \mathrm{COOH} \leftrightarrow \mathrm{COOH}$ interactions.

MelAc stable clusters may be the reason for its inactivity in comparison with BetAc, Bet, and Lup..$^{30}$ Inactivity of MelAc can also be caused by its inability to permeate the cell membrane. Considering this possibility, we calculate the theoretical lipophilicity of Bet, BetAc, Lup, and MelAc. Lipophilicity is related to the partition coefficient $(\log \mathrm{P})$, this last property associated with the partition of compounds between two immiscible phases (in this case, an octanol/ water mixture). The higher the coefficient, the greater the ability of a compound to permeate into the cell membrane. However, $\log \mathrm{P}$ cannot be too high because it would indicate insolubility in water (the biological solvent).

ChemAxon $^{57}$ and ALOGPS ${ }^{66}$ parameters were used to calculate $\log \mathrm{P}$ (Table 3). All four compounds exhibited acceptable lipophilicity, with values in the range of common drugs. ${ }^{67-71}$ MelAc presents the smallest log P, but the difference is not expressive enough to indicate inactivity. MelAc could present less activity in comparison with the other LPT, but inactivity is not expected. As the carboxyl group is considered important to the activity of BetAc, ${ }^{29,72}$ a reasonable explanation for the inactivity of MelAc is the unavailability of both carboxyls during biochemical interactions. The five comparative compounds considered in Table 3 have important molecular aspects (Figure S8, SI section). Messagenic acid A and artemisinin are the closer ones to LPT. When we compare MEPS for BetAc, MelAc and messagenic acid A, it is evident that the $\mathrm{C} 27$ region in MelAc is not more polar than in messagenic acid A (Figure S9, SI section). Polar groups usually have remarkable impact on molecular properties, and in this case the increase in polarity of $\mathrm{C} 27$ region should follow a coherence in terms of activity. The increase in polarity causes an increase in activity when we compare BetAc and messagenic acid A. Following this tendency, an at least
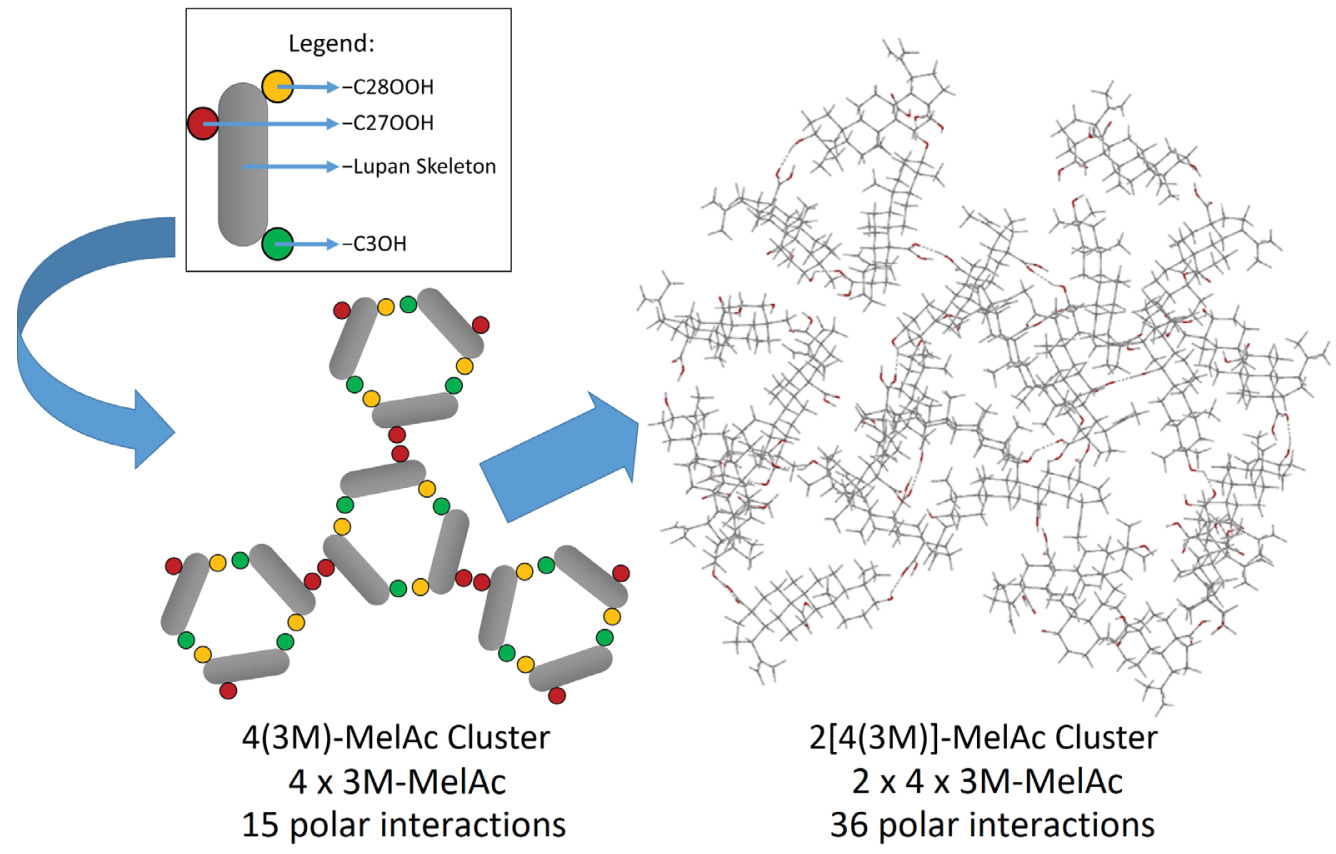

Figure 7. The 4(3M)-MelAc cluster model, based on hydrogen bonds, and the 2[4(3M)]-MelAc cluster model, both with a lot of hydrogen bond contributions. 
Table 3. Theoretical values of magnetic dipole moment $(\mu)$ and $\log \mathrm{P}$ for the lupane pentacyclic triterpenes and for five comparative compounds associated with membrane permeation and anti-plasmodial activity

\begin{tabular}{|c|c|c|c|c|}
\hline \multirow{2}{*}{ Compound $^{\mathrm{a}}$} & \multirow{2}{*}{$\mu^{\mathrm{b}} / \mathrm{D}$} & \multicolumn{3}{|c|}{$\log \mathrm{P}$} \\
\hline & & ALOGPS $^{\mathrm{c}}$ & Simplified ChemAxon model ${ }^{\mathrm{d}}$ & Consensus ChemAxon model ${ }^{\mathrm{d}}$ \\
\hline Bet & 0.507 & 5.34 & 6.43 & 6.17 \\
\hline BetAc & 1.949 & 5.34 & 6.96 & 6.64 \\
\hline Lup & 1.476 & 5.97 & 7.73 & 7.45 \\
\hline MelAc & 2.884 & 4.27 & 6.19 & 5.83 \\
\hline Messagenic acid $\mathrm{A}^{\mathrm{e}}$ & 3.242 & 6.19 & 9.07 & 8.09 \\
\hline Cholesterol $^{\mathrm{f}}$ & 1.447 & 7.02 & 6.87 & 7.11 \\
\hline Squalene $e^{g}$ & 0.404 & 8.64 & 9.37 & 10.42 \\
\hline Chloroquine & 4.438 & 5.28 & 3.81 & 3.93 \\
\hline Artemisinin $^{g}$ & 5.777 & 2.52 & 3.09 & 3.11 \\
\hline
\end{tabular}

aThe simplified molecular-input line-entry system (SMILES) of compounds was obtained with the Computer-Aided Drug Design (CADD) Group's

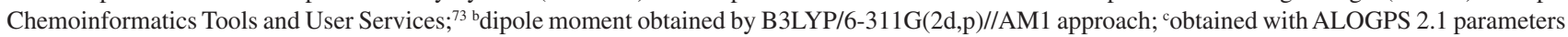
on Virtual Computational Chemistry Laboratory; ${ }^{66}$ dobtained with ChemAxon parameters on MarvinSketch $2017 ;{ }^{57}$ BetAc derivative with a ester/eno/ fenol group at C27 and interesting activity against Plasmodium, ${ }^{31}$ freference compound in cell membrane permeation; ${ }^{\mathrm{g}}$ considering anti-plasmodial activity, squalene is an unsaturated acyclic hydrocarbon with great activity, and chloroquine and artemisinin are seen as references in activity. ${ }^{74}$ Bet: betulin; BetAc: betulinic acid; Lup: lupeol; MelAc: melaleucic acid.

comparable effect should occur with MelAc. Thus, the polar region at $\mathrm{C} 27$ of MelAc could not be an argument for his inactivity.

It can be noted that artemisinin has a low $\log \mathrm{P}$, whereas squalene has a high $\log \mathrm{P}$, but both compounds exhibit high activity. ${ }^{74}$ The two methods of obtaining $\log \mathrm{P}$ involve different conceptions, but there is a coherence of the obtained data, which is the variation of values from one LPT to the other. Since log P for Bet, BetAc, Lup, and MelAc are close to those of comparative compounds, arguments based on this property should consider that some compounds, with low or high log P, exhibit great activity.

The MelAc ability to form larger stable clusters has physicochemical implications in comparison with BetAc. Characteristics such as molecular mobility, availability for reactions, and points of phase change will be affected. This is corroborated while comparing the differences in the melting and boiling temperatures of the two compounds (Table S4, SI section). Some of these values are experimental, but others were not found in literature, because of which we used values calculated with parameterized softwares., ${ }^{4,75-77}$

Since MelAc has a structure with two opposite carboxyls, making it harder to pack in a more compact solid state, it would be expected to have a lower melting point than BetAc. However, its melting point is almost $65{ }^{\circ} \mathrm{C}$ higher, suggesting very high order in the solid phase, and greater interaction and stability. Thus, it is expected that MelAc crystals, with more hydrogen bonds, will resist melting more than BetAc. However, it is the boiling points that strongly suggest the formation of stable clusters of MelAc. The results show that MelAc changes to gaseous phase at $65{ }^{\circ} \mathrm{C}$ above BetAc. For similar structures, such a change should occur at nearby temperatures. The logical conclusion is the existence of hydrogen bonds stronger than those verified in BetAc, which in turn point to the presence of stable clusters. Other properties, such as enthalpy of vaporization, density, and surface tension, corroborate the same reasoning.

The theoretical affinities in the formation of substrateprotein complexes (obtained with AD Vina) suggest that the four LPT would have the same tendency to bind with the proteins. The docking modes receive the name Mn, where $\mathrm{n}$ is the energetic position, and the higher the $\mathrm{n}$, the lower the affinity. Table 4 shows redocking results to human serum albumin (HSA), to three malaria-associated proteins, to a protein complexed with chloroquine, and to a protein complexed with BetAc. Each protein region (PR) was chosen considering the numbers of ligands on each PDB file, and not all have two PR for docking. In these eight protein redockings, five had the modes of higher affinity coincident with lower root mean square deviation (RMSD). The three exceptions show that AD Vina finds modes with better affinities, although it also finds modes of lower affinities with better RMSD: M4/2BSX, M4/2BNX coincidentally for both PR, and M6/1CET.

In Table 5, the affinities of NL suggest that MelAc should behave similarly to other LPT. For PR1/1NHW, BetAc and Lup dock with highest affinity at specific sites different from those for Bet and MelAc. In all other proteins and PR, the NL dock with highest affinities at the same specific sites. The four NL exhibit affinities comparable to 
Table 4. Results of OL redocking on selected proteins, considering modes with higher affinities and lower RMSD

\begin{tabular}{|c|c|c|c|c|c|}
\hline \multirow{2}{*}{ PDB file } & \multirow{2}{*}{ Mode } & \multicolumn{2}{|c|}{ Affinity / $\left(\mathrm{kJ} \mathrm{mol}^{-1}\right)$} & \multicolumn{2}{|c|}{$\mathrm{RMSD} / \AA$} \\
\hline & & PR1 & PR2 & PR1 & PR2 \\
\hline $2 \mathrm{BXB}^{\mathrm{a}}$ & M1 & -37.238 & -37.238 & 1.272 & 1.022 \\
\hline $2 \mathrm{BXC}^{\mathrm{a}}$ & M1 & -38.911 & -40.585 & 0.928 & 0.904 \\
\hline $2 \mathrm{BXD}^{\mathrm{a}}$ & M1 & -40.166 & -37.238 & 0.477 & 0.686 \\
\hline $1 \mathrm{NHW}^{\mathrm{b}}$ & M1 & -38.074 & -38.074 & 0.840 & 0.521 \\
\hline $2 \mathrm{BSX}$ & M1 & -28.870 & - & 2.576 & - \\
\hline $2 \mathrm{BSX}^{\mathrm{c}}$ & M $4^{g}$ & -25.941 & - & 0.848 & - \\
\hline $4 \mathrm{BNX}^{\mathrm{d}}$ & M1 & -50.208 & -49.790 & 4.667 & 6.599 \\
\hline $4 \mathrm{BNX}^{\mathrm{d}}$ & M4 $4^{\mathrm{g}}$ & -47.279 & -48.534 & 0.567 & 0.332 \\
\hline $1 \mathrm{CET}^{\mathrm{e}}$ & M1 & -24.267 & - & 2.644 & - \\
\hline $1 \mathrm{CET}^{\mathrm{e}}$ & M6 $6^{g}$ & -22.594 & - & 1.678 & - \\
\hline $5 \mathrm{LSG}^{\mathrm{f}}$ & M1 & -34.309 & - & 0.395 & - \\
\hline
\end{tabular}

aPublished by Ghuman et al. $;{ }^{78}$ published by Perozzo et al. $;{ }^{79}$ published by Schnick et al. $;{ }^{80}$ dpublished by Cukier et al. $;{ }^{81}$ epublished by Read et al. $;{ }^{82}$ ${ }^{\mathrm{f}}$ published by Brusotti et al. ${ }^{83} \mathrm{~g}$ modes with lower affinities, but better RMSD. PDB: Protein Data Bank; RMSD: root mean square deviation; PR1, PR2: protein regions 1 and 2, respectively.

OL of each protein. In many comparisons between LPT, MelAc shows the lowest affinities, but with relatively small difference. The highest inferiority in affinity of MelAc occurs at PR1/5LSG, where the smallest difference is $2.092 \mathrm{~kJ} \mathrm{~mol}^{-1}$ compared to Bet. Considering the affinities, we cannot say that MelAc would be unable to bind proteins. It can also be noted that, in PR $1 / 2 \mathrm{BXC}$ and PR2/2BXB, MelAc shows greater affinities than BetAc.

The docking modes also show the proximities in the LPT couplings with the proteins. This strongly suggests that the polar groups have partial effect on activity, since the affinities were close. In the present study, BetAc and MelAc receive more attention, and are more highlighted. For the next figures, the following highlights should be considered: (i) the OL without redocking are in blue tubes, in the original positions of PDB; (ii) after redocking, if the mode of highest affinity also has the lowest RMSD, this OL mode will be in green tubes; if these modes are different, the mode of lowest RMSD will be in green tubes, and the mode of highest affinity will be in blue tubes; and (iii) the NL modes after docking are colored by types of atoms, with Bet and Lup in lines, and BetAc and MelAc in tubes.

The proximities in the substrate-protein coupling modes (comparing only BetAc and MelAc) are associated with the overlaps of individual modes, $\mathrm{Ma} \leftrightarrow \mathrm{Mb}$, where $\mathrm{a}$ and $\mathrm{b}$ are the energetic positions. The modes of highest affinity (Ma) are set as reference and are shown in colored tubes by types of atoms. The modes of the other compound $(\mathrm{Mb})$ with best

Table 5. Affinities of compounds docked at the same specific sites for each file and protein region

\begin{tabular}{|c|c|c|c|c|c|c|c|c|}
\hline \multirow{3}{*}{ PDB file } & \multicolumn{8}{|c|}{ Higher affinity / $\left(\mathrm{kJ} \mathrm{mol}^{-1}\right)$} \\
\hline & \multicolumn{4}{|c|}{ PR1 } & \multicolumn{4}{|c|}{ PR2 } \\
\hline & Bet & BetAc & Lup & MelAc & Bet & BetAc & Lup & MelAc \\
\hline $2 \mathrm{BXB}$ & -35.146 & -36.401 & -37.656 & -35.146 & -31.798 & -31.798 & -33.054 & $-33.472^{\mathrm{a}}$ \\
\hline $2 \mathrm{BXC}$ & -34.309 & -35.564 & -36.401 & $-35.982^{\mathrm{a}}$ & -35.146 & -36.819 & -37.238 & -36.401 \\
\hline 2BXD & -32.217 & -36.401 & -34.727 & -35.564 & -35.564 & -36.819 & -37.656 & -35.982 \\
\hline 1NHW & -33.472 & $-35.564^{\mathrm{b}}$ & $-34.309^{b}$ & -34.309 & -35.564 & -37.656 & -35.146 & -33.054 \\
\hline 2BSX & -27.196 & -28.033 & -29.288 & -25.522 & - & - & - & - \\
\hline $4 \mathrm{BNX}$ & -31.798 & -30.962 & -31.798 & -30.125 & -30.962 & -30.962 & -31.380 & -30.125 \\
\hline 1CET & -24.267 & -24.686 & -25.941 & -22.594 & - & - & - & - \\
\hline 5LSG & -33.054 & -33.472 & -34.727 & -30.962 & - & - & - & - \\
\hline
\end{tabular}

${ }^{\mathrm{a} C}$ Cases where MelAc has higher affinity than BetAc; ${ }^{\mathrm{b} B e t A c}$ and Lup have these higher affinities at different specific sites than Bet and MelAc. PDB: Protein Data Bank; PR1, PR2: protein regions 1 and 2, respectively; Bet: betulin; BetAc: betulinic acid; Lup: lupeol; MelAc: melaleucic acid. 
coincidence are shown in green tubes. The best overlaps in each PR and specific sites are displayed separately from proteins for better visualization of the spatial coincidence.

The results for 1NHW show that the M1 $\leftrightarrow \mathrm{M} 1$ overlaps do not have a high coincidence, except at site 2 of PR2 (Figure 8). Nevertheless, all sites present overlaps that occur with better coincidence. The results for HSA also demonstrate coherent dockings (Figure S10, SI section). For 2BSX and 4BNX, the results also indicate that BetAc and MelAc have close molecular docking behaviors (Figure 9). In both proteins, the OL redocking reveals better docking conditions, highlighted in blue tubes, but the modes of lowest RMSD have lower affinities. The M1 $\leftrightarrow$ M1 overlaps do not have great coincidence. For these two proteins, the best overlaps are in general better than those observed for 1NHW. The overlaps for 1CET indicate that MelAc should have comparable activity to the other three LPT considered (Figure S11, SI section).
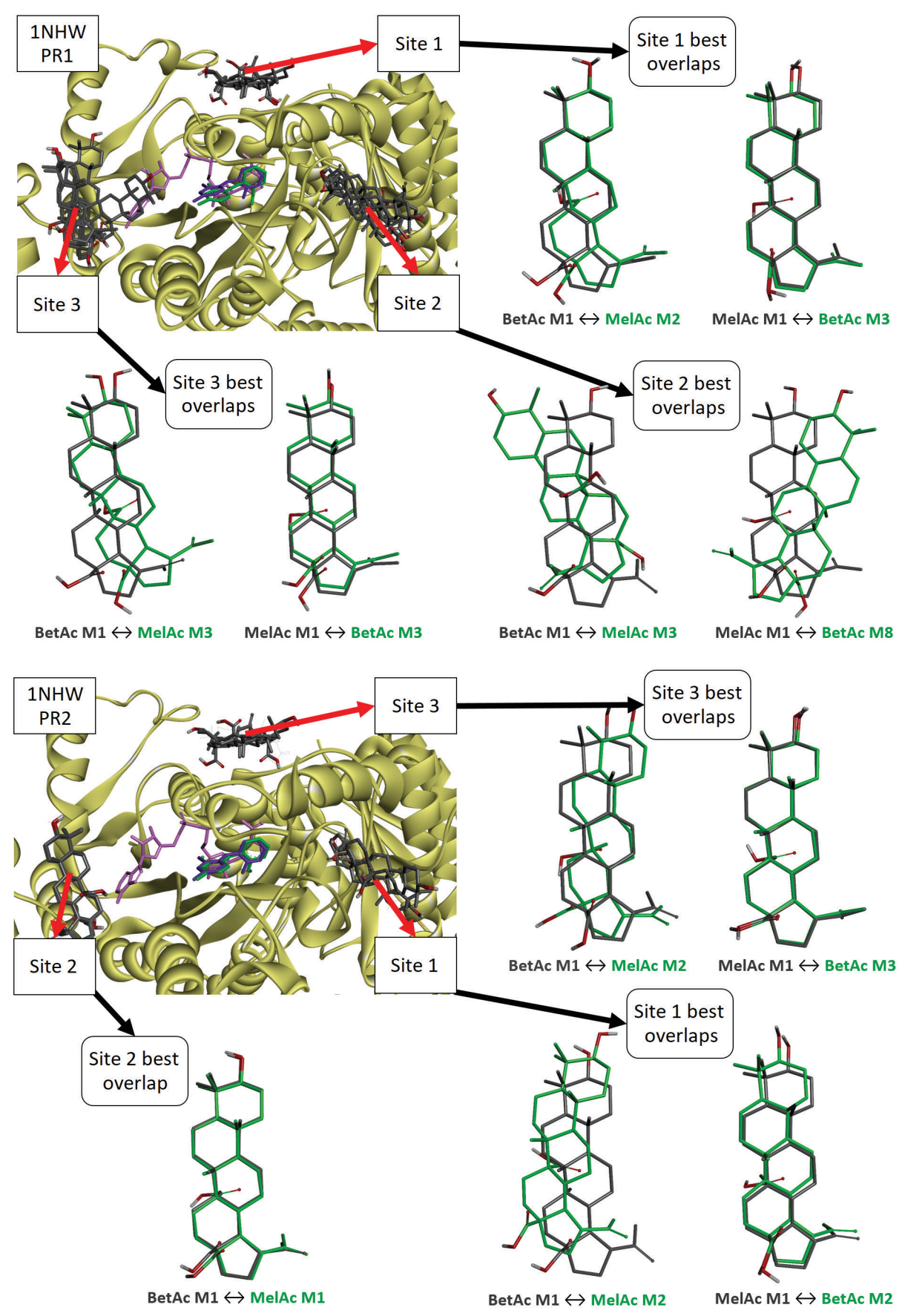

Figure 8. Redocked OL in 1NHW, with best affinity (in green) compared with non-redocked OL (in purple), and sites where compounds show better affinities, highlighting the best BetAc-MelAc overlaps (grey C-skeleton for higher affinity modes and green C-skeleton for closer overlap). 


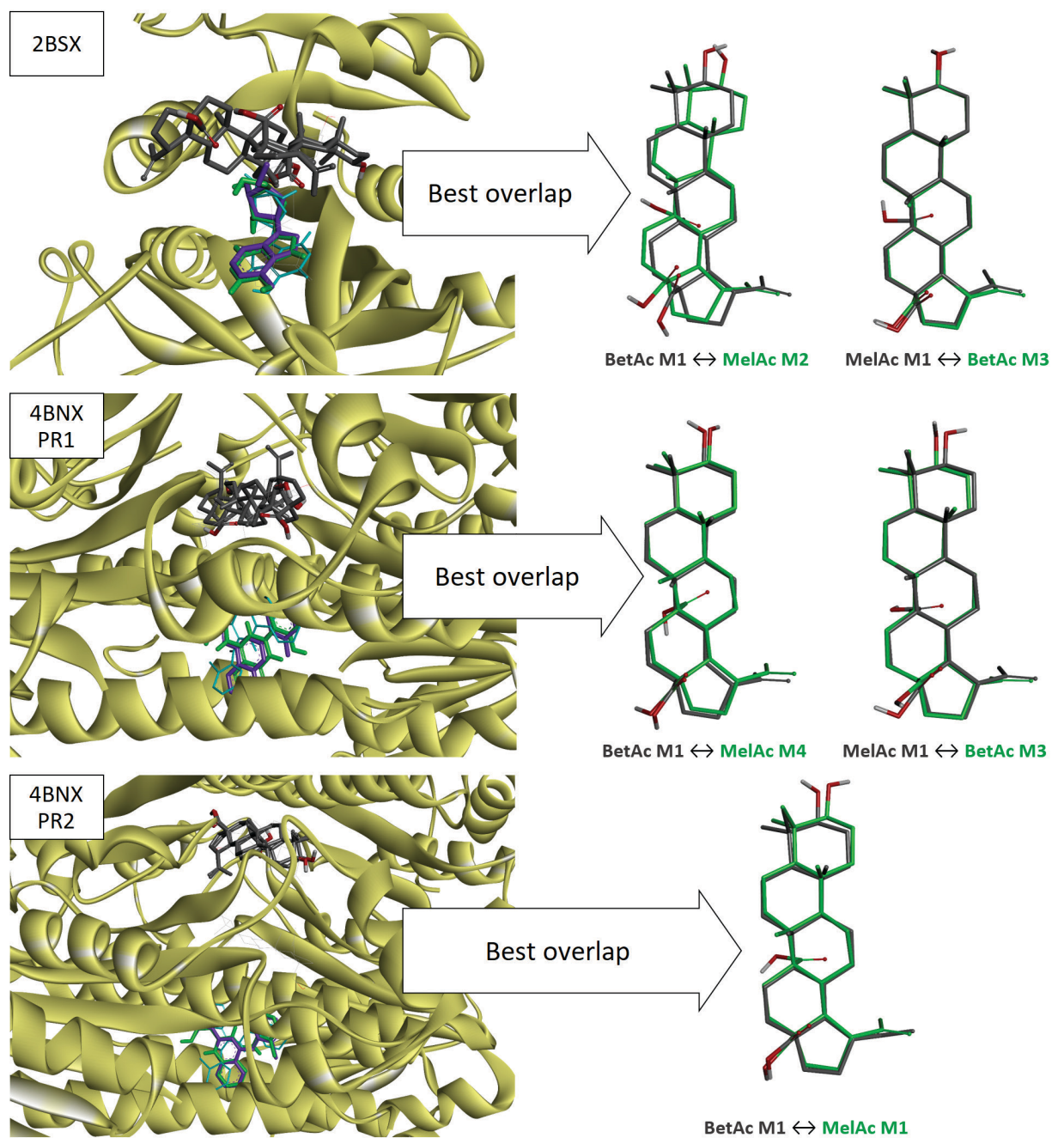

Figure 9. Redocked OL in 2BSX and 4BNX, with best affinity (in green) and best RMSD (in blue) compared with non-redocked OL (in purple), and sites where compounds show better affinities, highlighting best BetAc-MelAc overlaps (grey C-skeleton for higher affinity modes and green C-skeleton for closer overlap).

Thirteen theoretical dockings were performed with MelAc and the other three LPT, and all results suggest that they interact well with proteins. This indicates that Bet, BetAc, Lup, and MelAc present close mechanisms of interaction with the considered proteins, and no apparent reason for the differences in experimental activities was observed.

\section{Conclusions}

Theoretical results indicate that betulinic and melaleucic acids have very close structural and electronic properties, which does not justify the significant difference in their biological activity. Even their theoretical molecular dockings with proteins are very similar, and both compounds should be great ligands based on our data. In response, the present results allow us to suggest that $3 \mathrm{M}$ systems are sufficiently stable to act as a basis for clusters formation. The largest possible agglomerated structure of BetAc is the $3 \mathrm{M}$, but MelAc can expand $3 \mathrm{M}$ structures into larger and more stable clusters that can influence the biochemical activity. Thus, while considering the low activity of some organic molecules with respect to their high activity analogs, the cluster formation factor should be taken into account and be more investigated.

\section{Supplementary Information}

Supplementary information is available free of charge at http://jbcs.sbq.org.br as PDF file.

\section{Acknowledgments}

The authors thank Grupo de Química Teórica e Computacional, Universidade Federal do Amazonas (GQTC-UFAM), CNPq and FAPEAM. 


\section{References}

1. Bejar, E.; Amarquaye, A.; Che, C. T.; Malone, M. H.; Fong, H. H. S.; Int. J. Pharmacogn. 1995, 33, 25.

2. Brandao, M. G. L.; Lacaille-Dubois, M.; Teixera, M. A.; Wagner, H.; Phytochemistry 1992, 31, 352.

3. Cardoso, S. W.; Torres, T. S.; Santini-Oliveira, M.; Marins, L. M. S.; Veloso, V. G.; Grinsztejn, B.; Braz. J. Infect. Dis. 2013, $17,464$.

4. Chopra, C. S.; Cole, A. R. H.; Theiberg, K. J. L.; White, D. E.; Arthur, H. R.; Tetrahedron 1965, 21, 1529.

5. Phillipson, J. D.; Phytochemistry 2007, 68, 2960.

6. Steinhoff, B.; Phytomedicine 2013, 20, 1047.

7. Vieira, T. R.; Barbosa, L. C. A.; Maltha, C. R. A.; Quim. Nova 2004, 27, 536.

8. Fulda, S.; Friesen, C.; Los, M.; Scaffidi, C.; Mier, W.; Benedict, M.; Nuñez, G.; Krammer, P. H.; Peter, M. E.; Debatin, K. M.; Cancer Res. 1997, 57, 4956.

9. Fulda, S.; Jeremias, I.; Steiner, H. H.; Pietsch, T.; Debatin, K. M.; Int. J. Cancer 1999, 82, 435.

10. Baratto, L. C.; Porsani, M. V.; Pimentel, I. C.; Netto, A. B. P.; Paschke, R.; Oliveira, B. H.; Eur. J. Med. Chem. 2013, 68, 121.

11. Fulda, S.; Int. J. Mol. Sci. 2008, 9, 1096.

12. Fujioka, T.; Kashiwada, Y.; Kilkuskie, R. E.; Cosentino, L. M.; Ballas, L. M.; Jiang, J. B.; Janzen, W. P.; Chen, I.; Lee, K.; J. Nat. Prod. 1994, 57, 243.

13. Mayaux, J. F.; Bousseau, A.; Pauwels, R.; Huet, T.; Hénin, Y.; Dereu, N.; Evers, M.; Soler, F.; Poujade, C.; De Clercq, E.; Le Pecq, J. B.; Proc. Natl. Acad. Sci. U. S. A. 1994, 91, 3564.

14. Kashiwada, Y.; Hashimoto, F.; Cosentino, L. M.; Chen, C.; Garrett, P. E.; Lee, K.; J. Med. Chem. 1996, 39, 1016.

15. Steele, J. C. P.; Warhurst, D. C.; Kirby, G. C.; Simmonds, S. J.; Phytother. Res. 1999, 13, 115.

16. Mukherjee, P. K.; Saha, K.; Das, J.; Pal, M.; Saha, B. P.; Planta Med. 1997, 63, 367.

17. Recio, M. C.; Giner, R. M.; Manez, S.; Gueho, J.; Julien, H. R.; Hostettmann, K.; Rios, J. L.; Planta Med. 1995, 61, 9.

18. Safayhi, H.; Sailer, E. R.; Planta Med. 1997, 63, 487.

19. Chandramu, C.; Manohar, R. D.; Krupadanam, D. G. L.; Dashavantha, R. V.; Phytother. Res. 2003, 17, 129.

20. Cichewicz, R. H.; Kouzi, S. A.; Med. Res. Rev. 2004, 24, 90.

21. Yogeeswari, P.; Sriram, D.; Curr. Med. Chem. 2005, 12, 657.

22. Zhao, S.; Huang, Z.; Gao, J.; Bull. Korean Chem. Soc. 2011, 32,1368

23. Innocente, A. M.; Silva, G. N. S.; Cruz, L. N.; Moraes, M. S.; Nakabashi, M.; Sonnet, P.; Gosmann, G.; Garcia, C. R. S.; Gnoatto, S. C. B.; Molecules 2012, 17, 12003.

24. Nyasse, B.; Nono, J.; Nganso, Y.; Ngantchou, I.; Schneider, B.; Fitoterapia 2009, 80, 32.

25. Moghaddam, M. G.; Ahmad, F. B. H.; Samzadeh-Kermani, A.; Pharmacol. Pharm. 2012, 3, 119.
26. Fisher, G. M.; Bua, S.; Del Prete, S.; Arnold, M. S. J.; Capasso, C.; Supuran, C. T.; Andrews, K. T.; Poulsen, S. A.; Int. J. Parasitol. 2017, 7, 61.

27. Koyama, F. C.; Chakrabarti, D.; Garcia, C. R. S.; Mol. Biochem. Parasitol. 2009, 165, 1.

28. Prades, J.; Vögler, O.; Alemany, R.; Gomez-Florit, M.; Funari, S. S.; Ruiz-Gutiérrez, V.; Barceló, F.; Biochim. Biophys. Acta 2011, 1808, 752.

29. Ziegler, H. L.; Franzyk, H.; Sairafianpour, M.; Tabatabai, M.; Tehrani, M. D.; Bagherzadeh, K.; Hägerstrand, H.; Staerk, D.; Jaroszewski, J. W.; Bioorg. Med. Chem. 2004, 12, 119.

30. Carmo, D. F. M.; Amaral, A. C. F.; Machado, M.; Lopes, D.; Echevarria, A.; Rosário, V. E.; Silva, J. R. A.; Pharmacogn. Mag. 2015, 11, 244.

31. Suksamrarn, A.; Tanachatchairatana, T.; Kanokmedhakul, S.; J. Ethnopharmacol. 2003, 88, 275.

32. Matsumoto, Y.; Iwamoto, J. I.; Honma, K.; Chem. Phys. Lett. 2013, 578, 43.

33. Dalai, S.; Rana, A.; Chowdhuri, D. S.; Bera, M.; Zangrando, E.; Inorg. Chim. Acta 2010, 363, 1052.

34. Shi, R. B.; Pi, M.; Jiang, S. S.; Wang, Y. Y.; Jin, C. M.; J. Mol. Struct. 2014, 1071, 23.

35. Springborg, M.; Thakkar, A. J.; Comput. Theor. Chem. 2013, 1021, 1.

36. Kawakami, T.; Taniguchi, T.; Shoji, M.; Kitagawa, Y.; Okumura, M.; Yamaguchi, K.; Polyhedron 2005, 24, 2382.

37. Hu, Y.; Sinnott, S. B.; Nucl. Instrum. Methods Phys. Res., Sect. B 2002, 195, 329.

38. Yingling, Y. G.; Garrison, B. J.; Nucl. Instrum. Methods Phys. Res., Sect. B 2003, 202, 188.

39. Qi, L.; Sinnot, S. B.; Surf. Sci. 1998, 398, 195.

40. Kusakari, M.; Gnaser, H.; Fujii, M.; Seki, T.; Aoki, T.; Matsuo, J.; Int. J. Mass Spectrom. 2015, 31, 383.

41. Balci, F. M.; Uras-Aytemiz, N.; Escribano, R.; Gómez, P. C.; Comput. Theor. Chem. 2014, 1038, 71.

42. Mondal, S.; Ghara, M.; Chattaraj, P. K.; Comput. Theor. Chem. 2015, 1071, 18

43. Samanta, A. K.; Ch'ng, L. C.; Reisler, H.; Chem. Phys. Lett. 2013, 575,1 .

44. Sameti, M. R.; Bayat, M.; Salehzadeh, S.; Arabian J. Chem. 2016, $9,41$.

45. Chen, C.; Li, W. Z.; Song, Y. C.; Weng, L. D.; Zhang, N.; Comput. Theor. Chem. 2012, 984, 85.

46. Nakanaga, T.; Buchhold, K.; Ito, F.; Chem. Phys. 2002, 277, 171.

47. Tabayashi, K.; Yamamoto, K.; Maruyama, T.; Yoshida, H.; Okada, K.; Tamenori, Y.; Suzuki, I. H.; Gejo, T.; Honma, K.; J. Electron Spectrosc. Relat. Phenom. 2011, 184, 134.

48. Zabardasti, A.; Solimannejad, M.; J. Mol. Struct.: THEOCHEM 2007, 810, 73. 
49. Benedetti, P. G.; Fanelli, F.; Drug Discovery Today 2010, 15, 859.

50. Igwe, I. O.; Ind. Crops Prod. 2004, 19, 185.

51. Matsushita, Y.; Ichimura, T.; Hikida, T.; Chem. Phys. Lett. 2002, 360,65 .

52. Frisch, M. J.; Trucks, G. W.; Schlegel, H. B.; Scuseria, G. E.; Robb, M. A.; Cheeseman, J. R.; Scalmani, G.; Barone, V.; Mennucci, B.; Petersson, G. A.; Nakatsuji, H.; Caricato, M.; Li, X.; Hratchian, H. P.; Izmaylov, A. F.; Bloino, J.; Zheng, G.; Sonnenberg, J. L.; Hada, M.; Ehara, M.; Toyota, K.; Fukuda, R.; Hasegawa, J.; Ishida, M.; Nakajima, T.; Honda, Y.; Kitao, O.; Nakai, H.; Vreven, T.; Montgomery Jr., J. A.; Peralta, J. E.; Ogliaro, F.; Bearpark, M.; Heyd, J. J.; Brothers, E.; Kudin, K. N.; Staroverov, V. N.; Kobayashi, R.; Normand, J.; Raghavachari, K.; Rendell, A.; Burant, J. C.; Iyengar, S. S.; Tomasi, J.; Cossi, M.; Rega, N.; Millam, J. M.; Klene, M.; Knox, J. E.; Cross, J. B.; Bakken, V.; Adamo, C.; Jaramillo, J.; Gomperts, R.; Stratmann, R. E.; Yazyev, O.; Austin, A. J.; Cammi, R.; Pomelli, C.; Ochterski, J. W.; Martin, R. L.; Morokuma, K.; Zakrzewski, V. G.; Voth, G. A.; Salvador, P.; Dannenberg, J. J.; Dapprich, S.; Daniels, A. D.; Farkas, Ö.; Foresman, J. B.; Ortiz, J. V.; Cioslowski, J.; Fox, D. J.; Gaussian 09, Revision D.01; Gaussian, Inc., Wallingford, CT, USA, 2013.

53. Tomasi, J.; Mennucci, B.; Cammi, R.; Chem. Rev. 2005, 105, 2999.

54. Suleimen, E. M.; Van Hecke, K.; Van Meervelt, L.; Deborggraeve, W.; Dehaen, W.; J. Struct. Chem. 2013, 54, 189.

55. Trott, O.; Olson, A. J.; J. Comput. Chem. 2010, 31, 455.

56. Dassault Systèmes BIOVIA; Discovery Studio 2017 R2, Version v17.2.0.16349; Dassault Systèmes, San Diego, CA, USA, 2017.

57. ChemAxon; MarvinSketch, Version 17.27.0; ChemAxon Ltd., Cambridge Innovation Center, Cambridge, MA, USA, 2017.

58. Hall, S. R.; Maslen, E. N.; Acta Crystallogr. 1965, 18, 265.

59. Pînzaru, S. C.; Leopold, N.; Kiefer, W.; Talanta 2002, 57, 625.

60. Fălămaş, A.; Pînzaru, S. C.; Dehelean, C. A.; Peev, C. I.; Soica, C.; J. Raman Spectrosc. 2011, 42, 97.

61. Pai, S. R.; Nimbalkar, M. S.; Pawar, N. V.; Dixit, G. B.; Ind. Crops Prod. 2011, 34, 1458.

62. Pearson, R. G.; Songstad, J.; J. Am. Chem. Soc. 1967, 89, 1827.

63. Parr, R.; Pearson, G.; J. Am. Chem. Soc. 1983, 105, 7512.

64. Parr, R. G.; Weitao, Y.; Density-Functional Theory of Atoms and Molecules, vol. 1, $1^{\text {st }}$ ed.; Oxford University Press: New York, 1994.
65. Parr, R.; Szentpaly, L.; Liu, S.; J. Am. Chem. Soc. 1999, 121, 1922.

66. http://www.vcclab.org/lab/alogps/, accessed in May 2018.

67. Tetko, I. V.; Gasteiger, J.; Todeschini, R.; Mauri, A.; Livingstone, D.; Ertl, P.; Palyulin, V. A.; Radchenko, E. V.; Zefirov, N. S.; Makarenko, A. S.; Tanchuk, V. Y.; Prokopenko, V. V.; J. Comput.-Aided Mol. Des. 2005, 19, 453.

68. Tetko, I. V.; Drug Discovery Today 2005, 10, 1497.

69. Vraka, C.; Nics, L.; Wagner, K. H.; Hacker, M.; Wadsak, W.; Mitterhauser, M.; Nucl. Med. Biol. 2017, 50, 1.

70. Silva, L. R.; Ferreira, M. M. C.; Quim. Nova 2003, 26, 312.

71. Pereira, D. G.; Quim. Nova 2007, 30, 171.

72. Bernard, P.; Scior, T.; Didier, B.; Hibert, M.; Berthon, J. Y.; Phytochemistry 2001, 58, 865.

73. https://cactus.nci.nih.gov/index.html, accessed in May 2018.

74. Banzouzi, J. T.; Soh, P. N.; Ramos, S.; Toto, P.; Cavé, A.; Hemez, J.; Benoit-Vical, F.; J. Ethnopharmacol. 2015, 173, 100.

75. http://www.matrixscientific.com/, accessed in May 2018.

76. Arthur, H. R.; Cole, A. R. H.; Thieberg, K. J. L.; White, D.; Chem. Ind. 1956, 35, 926.

77. ACD/Labs; ACD/Labs Percepta Platform, Version 15.01; Advanced Chemistry Development Inc., Toronto, ON, Canada, 2015.

78. Ghuman, J.; Zunszain, P. A.; Bhattacharya, I. P. A. A.; Otagiri, M.; Curry, S.; J. Mol. Biol. 2005, 353, 38.

79. Perozzo, R.; Kuo, M.; Sidhu, A. B. S.; Valiyaveettil, J. T.; Bittman, R.; Jacobs Jr., W. R.; Fidock, D. A.; Sacchettini, J. C.; J. Biol. Chem. 2002, 277, 13106.

80. Schnick, C.; Robien, M. A.; Brzozowski, A. M.; Dodson, E. J.; Murshudov, G. N.; Anderson, L.; Luft, J. R.; Mehlin, C.; Hol, W. G. J.; Brannigan, J. A.; Wilkinson, A. J.; Acta Crystallogr., Sect. D: Biol. Crystallogr. 2005, 61, 1245.

81. Cukier, C. D.; Hope, A. G.; Elamin, A. A.; Moynie, L.; Schnell, R.; Schach, S.; Kneuper, H.; Singh, M.; Naismith, J. H.; Lindqvist, Y.; Gray, D. W.; Schneider, G.; ACS Chem. Biol. 2013, 8, 2518.

82. Read, J. A.; Wilkinson, K. W.; Tranter, R.; Sessions, R. B.; Brady, R. L.; J. Biol. Chem. 1999, 274, 10213.

83. Brusotti, G.; Montanari, R.; Capelli, D.; Cattaneo, G.; Laghezza, A.; Tortorella, P.; Loiodice, F.; Peiretti, F.; Bonardo, B.; Paiardini, A.; Calleri, E.; Pochetti, G.; Sci. Rep. 2017, 7, 1.

Submitted: February 13, 2018

Published online: June 12, 2018 